\title{
The Effect of Digital Games on Behavior: Analysis of the General Learning Model
}

\author{
Mauricio Miranda Sarmet ${ }^{1}$ \\ Programa de Pós-Graduação em Psicologia Social, do Trabalho e das Organizações \\ da Universidade de Brasília, Brasília, DF, Brasil \\ Instituto Federal de Educação, Ciência e Tecnologia da Paraíba, João Pessoa, PB, Brasil \\ Ronaldo Pilati \\ Departamento de Psicologia Social e do Trabalho da Universidade de Brasília, \\ Brasília, DF, Brasil
}

\begin{abstract}
Digital games now occupy more space in people's lives. Since the popularization of personal computers, game consoles and portable devices more people spend more time exposed to a greater variety of games. Researchers in various fields have been studying the consequences of this phenomenon. Digital games are commonly associated with a range of antisocial behaviors such as aggression and murder. This paper's objective is to discuss evidence about the influence of games on human behavior, cognition, affect and arousal, based on the General Learning Model, focusing on available data related to aggression and prosociality. Several criticisms of the extant research are discussed: the poor quality of the measures used, the games used in research and the explanatory power of this model. Finally, a research agenda to improve work is this field is proposed.
\end{abstract}

Keywords: Digital games, General Learning Model, cognition.

\section{Efeito dos Jogos Digitais no Comportamento: Análise do General Learning Model}

\section{Resumo}

Os jogos digitais vêm ocupando um espaço maior na vida das pessoas. Com a popularização de computadores pessoais, consoles de videogame e artefatos portáteis, uma quantidade maior de pessoas passa mais tempo exposta a diferentes jogos e diversas áreas do conhecimento estudam quais consequências estão associadas a este fenômeno. Além disso, os jogos digitais são comumente associados a uma série de comportamentos antissociais, como agressões e assassinatos. O objetivo do presente trabalho é discutir um conjunto de evidências sobre a influência de jogos nas dimensões de comportamento, cognição, afeto e excitação, com base no General Learning Model, tendo como foco dados relacionados à agressividade e à prosocialidade. Além disso, busca-se apresentar as principais críticas associadas às pesquisas da área, como a qualidade das medidas utilizadas, a seleção de jogos para pesquisas e o potencial explicativo do modelo. Por fim, sugere-se agenda de pesquisa com o intuito de contribuir com o aprimoramento deste campo de investigação.

Palavras-chave: Jogos digitais, General Learning Model, cognição.

Mailing address: SQSN 313 - D - 602, Brasília, DF, Brazil 70766-040. E-mail: msarmet@gmail.com and rpilati@gmail.com

Financial support: National Counsel of Technological and Scientific Development (CNPq). 


\section{Efecto de los Videojuegos en el Comportamiento: Análisis del General Learning Model}

\section{Resumen}

Juegos digitales han estado ocupando un gran espacio en la vida de las personas. Con la popularización de las computadoras personales, consolas de videojuegos y los artefactos portátiles, una gran cantidad de personas que pasan más tiempo expuestos a diferentes juegos y las diferentes áreas de conocimiento a estudiar qué consecuencias son associadas a este fenómeno. Además, los juegos digitales son comúnmente asociados con una serie de conductas antisociales, como la agresión y el asesinato. El objetivo de este trabajo es discutir una serie de pruebas com respecto a la influencia de los juegos en las dimensiones de la conducta, la cognición, el afecto y la excitación, con base en el General Learning Model, centrándose en los datos relativos a la agresión y prosocialidad. Además, presenta las principales críticas asociadas a la investigación deste objeto, tales como la calidad de las medidas utilizadas, la selección de la investigación de juegos y el poder explicativo del modelo. Por último, se sugiere una agenda de investigación con el fin de contribuir a la mejora de este campo de investigación.

Palabras clave: Juegos digitales, General Learning Model, cognición.

The emergence of new media inevitably results in discussion of their effects beneficial or harmful on human behavior. Such discussion is justified by the fact that mass communication and mass entertainment systems such as radio, film and television can reach a large and socially diverse population. The same is true of digital games; digital games in various formats (personal computers, game consoles, tablets and mobile phones) are currently part of everyday life for people of various ages and socioeconomic levels. A growing proportion of people are consumers of a very rapidly growing industry (Mäyrä, 2008; McGonigal, 2011).

One of the most controversial issues in the study of digital games is the possible association between aggressive behavior and the exposition of violent games (for example, the Columbine shootings in the United States and the Realengo school incident in Rio de Janeiro in Brazil). Besides the description of the crime itself, the news media usually attempt to relate it with several aspects of the killer's life, being video game playing one of them. This leads to implicit or explicit assumptions that there is a causal relationship between the type of game that individuals play and the way they behave outside the game context.

The authors of systematic reviews and meta-analyses of this subject claim to have found enough evidence to conclude that there is a causal relationship between exposure to digital games and certain behaviors (for example, Anderson \& Bushman, 2001; Anderson et al., 2010; Barlett, Anderson, \& Swing, 2009; Fischer, Greitemeyer, Kastenmüller, Vogrincic, \& Sauer, 2011; Greitemeyer \& Mügge, 2014). Although the methodology and practical significance of these studies has been criticized (Elson \& Ferguson, 2014; Ferguson, 2007, 2009a, 2009b; Ferguson \& Dyck, 2012), some authors suggest that future research should not dwell further on whether or not this relationship exists, but on the processes underlying it (Bushman \& Huesmann, 2014). These authors argue that research should focus on how games can influence players' behavior and what variables are involved in this relationship. However, it is important to highlight the scarcity of studies assessing the premises on which the theoretical model is based. In particular there is a lack of evidence on how the characteristics of a digital game influence stimulus processing (automatic and controlled) and the probability of certain behaviors.

This article discusses the empirical evidence relating to how digital games affect human behavior, focusing on behavioral processes and research methodology. There is a wide variety of evidence however this paper is largely 
limited to discussion of the effects of aggressive and prosocial content. The paper also includes a critique of methodology in these studies, specifically the choice of stimuli and methods of measurement. Questions about the explanatory potential of the theoretical model are also raised and a research agenda based on the two-process model of information processing is advocated as the best approach to improving our understanding of the relationship between digital games and human behavior.

First we present the theoretical model most commonly used in studies of the relationship between digital games and behavior. Then we present empirical evidence relating to the cognitive, affective and arousing effects of video games on human behavior. Finally, we discuss the most common criticisms of this model and suggest alternatives for future research.

\section{General Learning Model}

The General Learning Model (GLM) proposes main dimensions involved in the study of the influence of different media on behavior, as well as different routes by which this influence seems to occur (Buckley \& Anderson, 2006). The GLM is based on Anderson and Bushman's General Aggression Model (2002) and was developed to account for other behavioral phenomena.

One of the main tenets of the GLM is that the media products have both immediate (or short-term) effects, and long-term effects due to repeated exposure to the same or similar stimuli. It is argued that certain structural and procedural characteristics of digital games create a learning context that can lead to enduring changes in affect, cognition, arousal and behavior (Swing, Gentile, \& Anderson, 2009). These features are: (a) the ability to control and adjust the difficulty level of a game; (b) repeated demand for certain skills (a characteristic of training contexts); (c) an active learning process (players must intentionally engage in gaming experience to achieve the goals of a particular game); (d) immediate feedback on the player's actions, including rewards for good performance; (e) use of skills which may generalize to other contexts (similar skills are required in different games e.g. first person shooter games usually require similar skills). It is suggested that these features explain why digital games have more impact on behavior than exposure to other media in which interactivity and constant feedback are not usual.

The GLM is grounded in several theories of cognition and human learning: Bandura's theories of social learning, Berkowitz's neo-associationist theory of memory, Zillmann's excitation transfer theory, Husmann's script theory and Crick and Dodge's social information processing theory (Barlett \& Anderson, 2013; Buckley \& Anderson, 2006). It has been argued that the GLM is, to a certain extent, corroborated by the large number of studies that support those theories (Prot \& Anderson, 2013).

The GLM (Figure 1) proposes that there are two different types of input variables. First there are personal variables related to attitudes, beliefs, goals, previous experiences, and emotional states previous to media exposure; these are considered relatively stable. Then there are situational variables, these are contextual factors relating to the characteristics of the medium and context and the individual's understanding of the context in question. These variables influence the individual's internal state via a combination of cognitive, affective and arousal routes, which interact to produce an evaluation of the experience with the media.

According to the model, certain features of a situation can elicit compatible content in each route of the internal state and therefore result in a set of behaviors consistent to the content activated. The GLM posits that, for example, a violent game activates violencerelated content in memory, as well as affective states and arousal congruent with the violent context and hence results in more aggressive behavior. The GLM also assumes long-term effects involving the factual learning and behavior (from recurrent practice, as well as positive and negative feedback), and changes in personality (Buckley \& Anderson, 2006). The short- and long-term effects are thought to be due to different processes, however; short- 


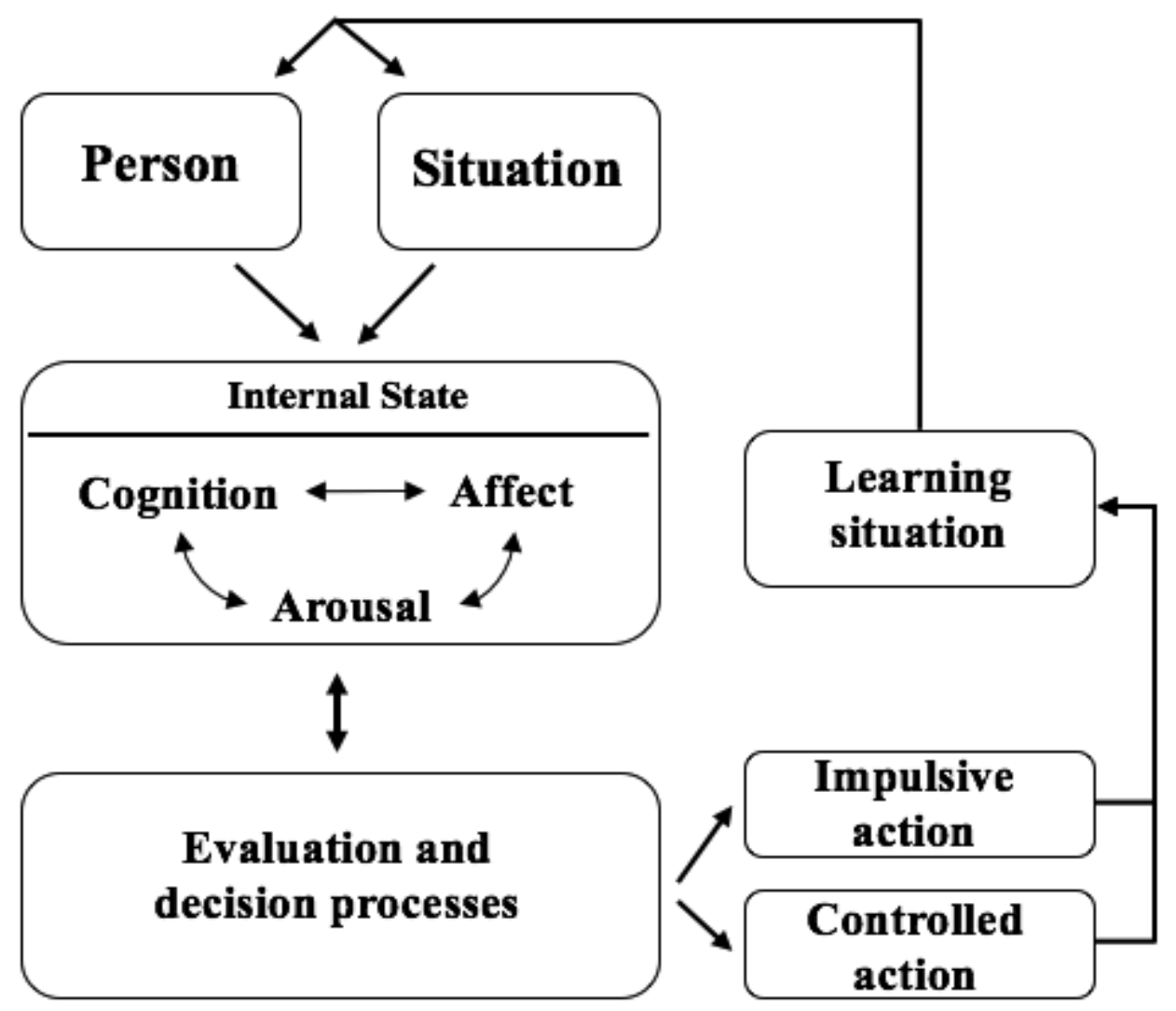

Figure 1. General Learning Model. Adapted from Buckley and Anderson (2006).

term effects may be related to priming, arousal and imitation, whereas long-term effects are thought to be based on learning by observation and activation and desensitization of emotional processes (Huesmann, 2007). In short, the GLM assumes that because playing digital games simulates particular real-world experiences, knowledge gained through gaming experience influences the perception and interpretation of game situations in the real world and may take the form of affective states, cognitive structures and behavioral scripts that can guide players' behavior in similar situations in the future. Because the gaming experience shares some of the characteristics of training, behavioral patterns activated during gaming may become more accessible to the player thus changing the way he or she interprets and deals with external situations.

An important aspect of a GLM interpretation of the effects of gaming relates to its account of how the information received from the gaming situation is processed. According to the
GLM stimuli are evaluated as soon as the individual is exposed to them (Barlett \& Anderson, 2013). Depending on the attentional resources devoted to this initial evaluation and its outcome a more controlled re-evaluation process can be activated (Anderson \& Dill, 2000). Automatic and controlled evaluation processes lead respectively to impulsive or controlled actions; this raises questions about the relationship between behavior and the way in which a stimulus is processed and the stored associations that exposure to it activates. The GLM suggests that the lack of cognitive resources or unsatisfying outcome evaluations may require the use of more controlled strategies of choice of behavior to be manifested.

This point, still scarcely debated in digital games literature, is important to understanding both the empirical results and their practical significance. If the propositions of the GLM are correct, behavior depends not solely on the type of digital game played (e.g. violent or prosocial): A number of other variables may mediate the in- 
fluence of the type of game on behavior, such as ability to filter initial assessments of stimuli in order to control the behavior to be manifested.

Several studies have investigated the relationship between the features of a game and its relevance on different dimensions of GLM. It is important to note that because of general nature of the model and the number of variables it contains, it is impossible to test it comprehensively in a single study. This means the evidence supporting the model consists of demonstrations of relationships between specific variables. The robustness of the model, according to its proponents, is a result of the analysis of several findings relating the media characteristics with each of the main routes (cognitive, affective and arousal) and with observed behavior. Next, we present some of the evidence for each of these routes.

\section{Empirical Evidence on the GLM}

In general investigations of the influence of digital games on the various routes of GLM use an experimental design in which relevant variables are controlled by the researcher (Greitemeyer \& Mügge, 2014). The type of game (e.g. prosocial; violent; neutral) is often manipulated as a between-subjects variable.

Several independent studies treating behavior as a dependent variable have suggested that elicited behavior is congruent with the type of game. It was observed, for example, that violent game play increased the frequency of aggressive behavior as measured by Competitive Reaction Time Task - CRTT (Anderson \& Dill, 2000; Carnagey \& Anderson, 2005). Exposure to violent games also tends to reduce donation behavior (Chambers \& Ascione, 2001), whereas prosocial games are associated with greater intent to help others (Greitemeyer \& Osswald, 2010; Jin, 2011; Peng, Lee, \& Heeter, 2010), selecting easier puzzles for other participants (Gentile et al., 2009; Saleem, Anderson, \& Gentile, 2012a) and a greater probability of helping a confederate by retrieving a pencil that has ostensibly fallen on the floor or assisting her in a simulated conflict situation (Greitemeyer \& Osswald, 2010).
Similarly, exposure to prosocial games appears to reduce the frequency of aggressive behavior (Greitemeyer, Agthe, Turner, \& Gschwendtner, 2011).

There is, however, no consensus on the relationship between games and behavior and some studies report that no such relationship exists (Ferguson, 2007; Sestir \& Bartholow, 2010; Tear \& Nielsen, 2013; Valadez \& Ferguson, 2012). Use of the CRTT to measure aggressive behavior has also been criticized on the grounds that it lacks ecological validity (Elson \& Ferguson, 2014), that the instructions, procedures and scales have not been standardized and that data analysis strategies also vary between studies (Elson, Mohseni, Breuer, Scharkow, \& Quandt, 2014). The critics argue that these inconsistencies weaken the instrument and that in some cases the conclusion may vary according to how the data is prepared and analyzed.

Most evidence suggests that the characteristics of the game influence memory activation and cognitive accessibility. For example, Anderson and Dill (2000) exposed participants to a violent game (Mortal Kombat) or a neutral game (Myst) and then asked them to perform a reading speed test. Response times for aggressive words were shorter in participants exposed to the violent game, which the authors interpreted as evidence that playing a violent game makes violent memory content more accessible.

Another measure of cognitive accessibility used is the Word Completion Task. In this task participants are presented with a set of word fragments which they must complete with the first word that comes to mind. Exposure to violent video games is associated with a greater probability of choosing violent words (Carnagey \& Anderson, 2005; Sestir \& Bartholow, 2010) whilst exposure to prosocial games tends to reduce aggressive cognitions (Greitemeyer et al., 2011; Greitemeyer \& Osswald, 2009). Other tasks used include completion of ambiguous stories, with the results suggesting that prosocial games can increase the accessibility of prosocial cognitions (e.g. Greitemeyer \& Osswald, 2010).

Other evidence on the cognitive route includes studies linking exposure to violent games 
with implicit aggressive self, on the basis of an Implicit Association Test (Bluemke, Friedrich, \& Zumbach, 2009; Uhlmann \& Swanson, 2004). Taking the active role players have on the interaction experience, as well as the rewarding system on aggressive behavior within the game, the results show that people associate more aggressive concepts to themselves than to others, when in contact with violent games. Other studies have linked exposure to digital games with effects on sexuality, gender stereotyping (Yao, Mahood, \& Linz, 2010) and perception of humanity (Bastian, Jetten, \& Radke, 2012) although additional evidence suggests that the cognitive effects of participation in digital games may not last long (Sestir \& Bartholow, 2010); an interval of 15 minutes between the game stage and measurement of cognition decreased aggressive cognitions. Finally, there is criticism of how cognition is operationalized. Bösche (2010), for example, presented evidence from a Lexical Decision Task suggesting that exposure to violent games increases the accessibility of both aggressive and prosocial memory content. Bösche suggested that both positive and negative cognitions should be measured in studies of the effect of games on cognition.

Studies of the impact of digital games on affect usually measure affective states using explicit scales, such as the Positive and Negative Affect Schedule and the State Hostility Scale, in an attempt to detect possible short-term changes. Systematic reviews and meta-analysis of the main empirical evidence on aggression (Anderson \& Bushman, 2001; Anderson et al., 2010) and prosociality (Greitemeyer \& Mügge, 2014) show that exposure to violent games tends to increase negative affect and reduce positive affect when compared to neutral or prosocial games. Other studies related to the affective route also consider, in addition to emotional states, desensitization procedures (Huesmann, 2007), cooperation and empathy (Greitemeyer, 2013b), as well as aggressive feelings (Jeong, Biocca, \& Bohil, 2012).

The relationship between the change in mood state induced by games and subsequent behavior is, however, unclear. For example, a study which compared violent and neutral games found that although groups exposed to violent games displayed higher levels of negative affect, aggressive behavior seemed to be more associated with the accessibility of negative cognitions than affective state (Carnagey \& Anderson, 2005). Similar results were found with respect to the relationship between affect and behavior in the case of prosocial games (Greitemeyer, 2011). Moreover, some studies have failed to find a relationship between game type and affective state (e.g. Greitemeyer \& Osswald, 2010; Valadez \& Ferguson, 2012). This suggests that changes in affective state following game playing might be associated with features of the game other than the type of game (or more specifically the level of violence or prosociality involved). It is also possible that a threshold applies to the 'strength' or quantity of game content such that the more violent a game is, the more likely it is to influence affect whilst games with minimal violence may not be sufficient to elicit an affective reaction. Problems with explicit measures of affect have also been cited as a possible explanation for the inconsistent findings in the literature (Elson \& Ferguson, 2014; Saleem, Anderson, \& Gentile, 2012b).

The arousal route is the one for which the evidence is most contradictory. Studies investigating the impact of games on arousal using physiological measures have produced positive results. For example, playing violent games was shown to produce significant changes in heart rate, blood pressure and galvanic skin response (Bailey, West, \& Anderson, 2009; Baldaro et al., 2004). In addition, systematic reviews have reported that there is a relationship between arousal and playing violent games (Anderson \& Bushman, 2001; Anderson et al., 2010). The only meta-analysis of the relationship between prosocial games and arousal found that the effects were inconsistent (Greitemeyer \& Mügge, 2014). Some studies have suggested, however, that effects of games playing on arousal may depend on variables such as the quality of the graphics or the extent to which they offer an 
immersive experience, rather than the content (violent, neutral or prosocial, for example) of the game (Bailey et al., 2009). There are also studies which have failed to find a relationship between game playing and arousal (Jeong et al., 2012).

In summary, the evidence presented to date raises some questions about the influence of digital games in human behavior and suggests new areas for investigation. These questions need to be addressed to identify and evaluate the effects of other variables that can moderate or mediate the relations between the variables described in GLM. The next section addresses some of these points, necessary in the current state of theoretical work on the subject.

\section{Studies of Mediating Variables}

Given the diversity of variables specified in the GLM, it is necessary to investigate possible mediators of the relationship between game playing and behavior. Mediation relationships might account for some of the apparent inconsistencies in the literature. Researchers studying both aggressive (Barlett \& Anderson, 2013) and prosocial behavior (Greitemeyer \& Osswald, 2009) have suggested that research on potential mediating variables is one of the most fruitful avenues for theoretical and methodological development in the field.

As noted earlier, some of the first empirical studies to show mediation dealt with the influence of games on cognition, using aggressive or prosocial behavior as a dependent variable (Anderson \& Dill, 2000; Carnagey \& Anderson, 2005; Greitemeyer et al., 2011; Greitemeyer \& Osswald, 2010). This suggests that cognitive processes, e.g. concepts, scripts and schema activated by exposure to the game and how the information is interpreted, may be central to the mechanism by which activated content evokes particular behaviors. Consistent with this argument, other mediators related to cognition also have empirical support.

In the case of violent games one possible mediator between video game content and violent behavior is hostile expectation bias (the ten- dency to attribute the actions of third parties to hostile intent). Studies investigating the effect of game type (violent or non-violent) on aggressive behavior have measured hostile expectation bias using an ambiguous story completion task in which participants are asked to list what the protagonist was thinking, feeling and doing throughout the story (Hasan, Bègue, \& Bushman, 2012; Hasan, Bègue, Scharkow, \& Bushman, 2013). Analysis suggested that exposure to violent game resulted in more hostile interpretations of the stories, and that more hostile interpretations were associated with more aggressive behavior (as measured with the CRTT). Other mediating variables which have been shown to relate to how individuals interpret the situation they are exposed to are perceived aggression (Greitemeyer, 2013a) and intergroup bias (Greitemeyer, 2013c).

Another important mediator of the effects of violent games on behavior is the extent to which the game offers the player an immersive experience (Jeong et al., 2012). Jeong et al. investigated how the realism of the game influenced its impact on players' aggression; they found that violent games only produced an effect on aggressive behavior when there was significant player immersion. It is important to note that effects of immersiveness were independent of other features of the game such as player perspective (first or third person) or arousal.

One of the main mediators of the effects of games on prosocial behavior is empathy, this is supported by longitudinal and cross-cultural studies (e.g. Prot et al., 2013). More specifically, games which elicit feelings of concern for others increase the probability of helping behavior, even in non-game contexts. Some game features, such as need for cooperation, may increase the probability that the game will elicit empathy towards particular others (Greitemeyer, 2013b).

The evidence presented so far, as well as the criticism associated with them, raise many questions that must be answered if we seek a better understanding of this phenomenon. Below we present some considerations and make some suggestions for future studies. 
Improving the Study of Games: Investigating Psychological Processes and the Development of New Research Tools

As discussed above, there is a considerable body of evidence supporting the hypothesis that exposure to a specific types of digital game influences how individuals interpret various situations inside and outside the context of the game and the way they behave in other contexts. We have discussed some of these experimental studies in order to illustrate the current state of the art in this field. However, there are still several gaps in the evidence and unresolved issues such as the difficulty of replicating effects, the importance of other variables (such as process-related variables and dispositional variables), problems with external validity, the small magnitude of the effects and the weakness of the instruments used in these studies (Elson \& Ferguson, 2014; Ferguson, 2009a, 2009b; Ferguson \& Kilburn, 2010). It is critical that we improve our understanding of the relationship between game playing and behavior in order to assess the adequacy of the GLM as an explanatory model.

Here we present two suggestions for refining experimental research in this field: one relates to the criteria used to select or develop games for use in experimental research. The second considers investigating the influence of automatic and controlled processes on players' evaluations and behavior.

\section{Considerations for Selection of Digital Games}

The choice of game for use in experimental research should take into account several factors. One of them regards to the nature (or content) of the game. The selection of games characterized as violent, neutral or prosocial is an example. When considering the game's content, the researcher should consider what he or she wants to elicit from the participant's exposure to the game and what are the dependent variables of interest. Games can, however, be classified on the basis of variables other than content, for instance game mechanics, story, graphics and sound elements, input devices and controls and complexity, some of which are included in the GLM as importance influences on behavior (see Barlett et al., 2009, for a synthesis). Considering the controlling issues for conducting experimental designs as well as the fact that the game features are situational elements that, according to the GLM, can influence the internal states of the individuals, two options can be used. Researcher can either select commercially available games or invest in developing games specifically for research (McMahan, Ragan, Leal, Beaton, \& Bowman, 2011).

The main advantages to using commercial games are their availability and superior greater ecological validity. Researcher must, however, confirm by pre-testing or by manipulation checks that a game has features which allow the independent variable of interest to be manipulated effectively in experimental conditions and that other variables are not compromising the results. This is usually achieved by asking participants about the perceived difficulty of the game, the excitement it evokes, its pleasantness, how satisfied they were with the gaming experience etc. for post facto analysis; however some authors have cast doubt on whether this strategy is robust enough to exclude the possibility that intervening variables may explain the results obtained (Elson \& Ferguson, 2014).

The use of digital games specifically developed for a research project is a strategy rarely used in this field, but it might help researchers to adopt the kind of rigorous methodology needed to for theoretical development. Custom-developed games have the advantage of allowing variables of interest to be controlled and manipulated more precisely, thus increasing the power of the analysis and the reliability of the findings. Developing a research game with similar properties to commercial games requires the involvement of professional developers and this requires resources not always available to research groups as well as being time consuming (McMahan et al., 2011). Also, attempts to produce games designed for research may result in a product which participants find very 
different from what they would class as a real game. Despite this reservation, such games may contribute to more robust methodology and should lead to better understanding of the cognitive, affective and behavioral processes related to playing digital games. Furthermore, it is essential to invest in developing games designed to test specific hypotheses about the processes involved, in order to overcome one of the barriers to development of robust theory in this research field.

\section{Investigation of Controlled and Automatic Processes}

The empirical evidence presented in this paper about the cognitive dimension reinforces its relevance to the influence of digital games on behavior. The GLM assumes the existence of evaluation and re-evaluation processes that, depending on the existence of sufficient cognitive resources and satisfactory feedbacks, may result in impulsive or controlled actions. However, there is insufficient empirical evidence to justify the inclusion of such elements in the model, or explain how they relate to other elements of the model (most importantly the game features and context). This fundamental gap in the evidence base casts doubt on the validity of many of the assumptions of the GLM.

The idea of a dual system of information processing is not unique to the field of digital games. The idea that there are processes, not accessible to consciousness, that influence how individuals perceive, interpret and act on the world has been discussed by researchers in various fields (Hassin, Uleman, \& Bargh, 2005). The dual system model is currently the dominant model of human cognition and it has been used in the study of processes associated with reasoning, judgment and decision-making, social perception, stereotypes, attitude change, among other constructs (Evans, 2008). It is based on evidence suggesting that human behavior is governed by a series of processes of which the individual may not be explicitly aware (Dijksterhuis \& Aarts, 2010).

For many years now there has been conside-rable interest among social cognition researchers in implicit processing, that occurs without an individual's attention and is outside his or her conscious control, because of the growing evidence supporting the dual model of information processing (Fiske \& Taylor, 2008; Kahneman, 2011). According to this model, there is a gradient in cognitive processing from purely automatic processing, in which the individual is unaware of the stimulus and does not explicitly control how it is processed, to controlled and conscious processing. In this sense, the implicit processing of information received from the environment systematically influence decisionmaking processes in different contexts (Bargh, Schwader, Hailey, Dyer, \& Boothby, 2012).

From this perspective, few studies seek to verify empirically the effect of implicit processes in understanding the influence of games on behavior. There have, however, been some investigations of how game content influences the implicit aggressive self (Bluemke et al., 2009; Uhlmann \& Swanson, 2004). Other questions relating to the role of implicit processing the relationship between game playing and behavior could be posed. It is reasonable to assume that in the absence of cognitive resources, automatic information processing predominates, because under these circumstances it is more difficult for an individual to exert control over information evaluation processes. In these cases, it is reasonable to argue what are the results expected from the exposure to different types of games, and the role of individual and situational variables. A plausible hypothesis is that personality traits (such as aggression, empathy and personality traits related to prosociality) might have more influence on behavior when players have limited cognitive resources. These and related hypotheses, would require a new approach to research. We suggest that new experimental research manipulating variable such as scarcity of cognitive resource and interference, as well as approaches that consider the dual process model, should be used to investigate the relationship between digital games and behavior. In other words variables concerning the cognitive route should be treated as an independent variable or mediator as well as a dependent variable. 
Manipulations of cognitive resources generally involve use of a concurrent task such as digit recall (Cavallo, Holmes, Fitzsimons, Murray, \& Wood, 2012; Conway \& Gawronski, 2013), or an ego depletion task (Fennis, 2011; Xu, Bègue, \& Bushman, 2012). Manipulating the availability of cognitive resources enables one to evaluate the role of controlled processes in determining the frequency of helping or aggressive behavior outside the game context. One possible hypothesis, for example, is that the lack of cognitive resources will increase the impact of dispositional variables on players' behavior.

\section{Final Considerations}

In recent years there has been an increase in research on the influence of digital games on behavior. This body of empirical evidence led to development of theoretical models seeking to describe and explain the relationship between games and behavior; the GLM is the most influential of these. Based on their assumptions, many important variables were systematically selected in order to investigate the influence of digital games in different dimensions of human functioning, such as behavior, cognition, affection and arousal (Anderson \& Bushman, 2001; Anderson et al., 2010; Barlett et al., 2009; Greitemeyer \& Mügge, 2014). Several theoretical criticisms of the GLM and the methods used to investigate it have been made, most relating to the quality of the instruments used, the choice of digital games; the very existence of a relationship between game playing and behavior has also been challenged (Elson \& Ferguson, 2014; Ferguson, 2009b). It has also been suggested that research in this field is influenced by biases that lend importance to an effect which has little, if any, practical relevance (Ferguson, 2007, 2008). We do not suggest that the empirical evidence supporting the GLM should be disregarded, nor that weaknesses in the evidence entirely invalidate its assumptions. Our aim was to review key studies in the field and suggest approaches that might address aspects of the data which are problematic for the GLM. We hope, in the words of Krahé (2014), to promote an attitude of fair play in this research field, by considering all the evidence, both positive and negative, relevant to the leading model of gaming and its influence on wider behavior.

In this paper we have sought to present both the evidence supporting the existence of a relationship between gaming and behavior and the most common criticisms associated with each type. Rather than providing a comprehensive analysis of the relevant literature our aim was to promote a fruitful discussion of the gaps in knowledge in the field and propose approaches which could be used to address them. Obviously our list of suggestions is not exhaustive; several other methodological changes are also needed including greater use of direct indicators of arousal and affect (such as physiological indicators) and longitudinal studies, in order to confirm that long-term exposure to digital games has a cumulative effect. We believe, however, that the dual systems model of information processing offers promising avenues of research, and together with greater attention to the role of game type, and development of digital games for use in experimental research, could improve understanding in the field.

\section{References}

Anderson, C. A., \& Bushman, B. J. (2001). Effects of violent video games on aggressive behavior, aggressive cognition, aggressive affect, physiological arousal, and prosocial behavior: A meta-analytic review of the scientific literature. Psychological Science, 12(5), 353-359. Retrieved from http://www.ncbi.nlm.nih.gov/ pubmed/11554666

Anderson, C. A., \& Bushman, B. J. (2002). Human aggression. Annual Review of Psychology, 53, $27-51$.

Anderson, C. A., \& Dill, K. (2000). Video Game Questionnaire. Journal of Personality, 6.

Anderson, C. A., \& Dill, K. E. (2000). Video games and aggressive thoughts, feelings, and behavior in the laboratory and in life. Journal of Personality and Social Psychology, 78(4), 772-790. doi:10.1037//O022-3514.78.4.772 
Anderson, C. A., Shibuya, A., Ihori, N., Swing, E. L., Bushman, B. J., Sakamoto, A., ...Saleem, M. (2010). Violent video game effects on aggression, empathy, and prosocial behavior in eastern and western countries: A meta-analytic review. Psychological Bulletin, 136(2), 151173. doi:10.1037/a0018251

Bailey, K., West, R., \& Anderson, C. A. (2009). The influence of video games on social, cognitive, and affective information processing. In J. Decety \& J. T. Cacioppo (Eds.), Handbook of social neuroscience (pp. 1-30). Oxford, UK: Oxford University Press.

Baldaro, B., Tuozzi, G., Codispoti, M., Montebarocci, O., Barbagli, F., Trombini, E., \& Rossi, N. (2004). Aggressive and non-violent videogames: Short-term psychological and cardiovascular effects on habitual players. Stress and Health, 20, 203-208. doi:10.1002/smi.1015

Bargh, J. A., Schwader, K. L., Hailey, S. E., Dyer, R. L., \& Boothby, E. J. (2012). Automaticity in social-cognitive processes. Trends in Cognitive Sciences, 16(12), 593-605. doi:10.1016/j. tics.2012.10.002

Barlett, C. P., \& Anderson, C. A. (2013). Examining media effects: The general aggression and general learning models. In E. Scharrer (Ed.), The International Encyclopedia of Media Studies (Vol. 5, pp. 108-127). Hoboken, NJ: Blackwell.

Barlett, C. P., Anderson, C. A., \& Swing, E. L. (2009). Video game effects--Confirmed, suspected, and speculative: A review of the evidence. Simulation \& Gaming, 40(3), 377-403. doi:10.1177/1046878108327539

Bastian, B., Jetten, J., \& Radke, H. R. M. (2012). Cyber-dehumanization: Violent video game play diminishes our humanity. Journal of Experimental Social Psychology, 48, 486-491. doi:10.1016/j.jesp.2011.10.009

Bluemke, M., Friedrich, M., \& Zumbach, J. (2009). The influence of violent and nonviolent computer games on implicit measures of aggressiveness. Aggressive Behavior, 35, 1-13. doi:10.1002/ ab.20329

Bösche, W. (2010). Violent video games prime both aggressive and positive cognitions. Journal of Media Psychology: Theories, Methods, and Applications, 22(4), 139-146. doi:10.1027/18641105/a000019
Buckley, K. E., \& Anderson, C. A. (2006). A theoretical model of the effects and consequences of playing video games. In P. Vorderer \& J. Bryant (Eds.), Playing video games - Motives, responses, and consequences (pp. 363-378). Mahwah, NJ: LEA.

Bushman, B. J., \& Huesmann, L. R. (2014). Twenty-five years of research on violence in digital games and aggression revisited. European Psychologist, 19(1), 47-55. doi:10.1027/1016-9040/ a000164

Carnagey, N. L., \& Anderson, C. A. (2005). The effects of reward and punishment in violent video games on aggressive affect, cognition, and behavior. Psychological Science, 16(11), 882889. doi:10.1111/j.1467-9280.2005.01632.x

Cavallo, J. V., Holmes, J. G., Fitzsimons, G. M., Murray, S. L., \& Wood, J. V. (2012). Managing motivational conflict: How self-esteem and executive resources influence self-regulatory responses to risk. Journal of Personality and Social Psychology, 103(3), 430-451. doi:10.1037/ a0028821

Chambers, J. H., \& Ascione, F. R. (2001). The effects of prosocial and aggressive videogames on children's donating and helping. Journal of Genetic Psychology, 148(4), 499-505.

Conway, P., \& Gawronski, B. (2013). Deontological and utilitarian inclinations in moral decision making: A process dissociation approach. Journal of Personality and Social Psychology, 104(2), 216-235. doi:10.1037/a0031021

Dijksterhuis, A., \& Aarts, H. (2010). Goals, attention, and (un)consciousness. Annual Review of Psychology, 61, 467-490. doi:10.1146/annurev. psych.093008.100445

Elson, M., \& Ferguson, C. J. (2014). Twenty-five years of research on violence in digital games and aggression. European Psychologist, 19(1), 33-46. doi:10.1027/1016-9040/a000147

Elson, M., Mohseni, M. R., Breuer, J., Scharkow, M., \& Quandt, T. (2014). Press CRTT to measure aggressive behavior: The unstandardized use of the competitive reaction time task in aggression research. Psychological Assessment, 26(2), 419432. doi:10.1037/a0035569

Evans, J. S. B. T. (2008). Dual-processing accounts of reasoning, judgment, and social cognition. Annual Review of Psychology, 59, 255-278. doi:10.1146/annurev.psych.59.103006.093629 
Fennis, B. M. (2011, June). Can’t get over me : Ego depletion attenuates prosocial effects of perspective taking. European Journal of Social Psychology, 585, 580-585. doi:10.1002/ejsp.828

Ferguson, C. J. (2007). Evidence for publication bias in video game violence effects literature: A meta-analytic review. Aggression and Violent Behavior, 12, 470-482. doi:10.1016/j. avb.2007.01.001

Ferguson, C. J. (2008). The school shooting/violent video game link: Causal relationship or moral panic? Journal of Investigative Psychology and Offender Profiling, 5(1-2), 25-37. doi:10.1002/ jip. 76

Ferguson, C. J. (2009a). Is psychological research really as good as medical research? Effect size comparisons between psychology and medicine. Review of General Psychology, 13(2), 130-136.

Ferguson, C. J. (2009b). Media violence effects: Confirmed truth or just another X-File? Journal of Forensic Psychology Practice, 9(2), 103-126. doi:10.1080/15228930802572059

Ferguson, C. J., \& Dyck, D. (2012). Paradigm change in aggression research: The time has come to retire the General Aggression Model. Aggression and Violent Behavior, 17(3), 220-228. doi:10.1016/j.avb.2012.02.007

Ferguson, C. J., \& Kilburn, J. (2010). Much ado about nothing: The misestimation and overinterpretation of violent video game effects in eastern and western nations: Comment on Anderson et al. (2010). Psychological Bulletin, 136(2), 174178; discussion 182-7. doi:10.1037/a0018566

Fischer, P., Greitemeyer, T., Kastenmüller, A., Vogrincic, C., \& Sauer, A. (2011). The effects of risk-glorifying media exposure on risk-positive cognitions, emotions, and behaviors: A metaanalytic review. Psychological Bulletin, 137(3), 367-390. doi:10.1037/a0022267

Fiske, S. T., \& Taylor, S. E. (2008). Dual modes in social cognition. In S. T. Fiske \& S. E. Taylor (Eds.), Social cognition: From brains to culture (pp. 25-50). New York: McGraw-Hill Higher Education.

Gentile, D. A., Anderson, C. A., Yukawa, S., Ihori, N., Saleem, M., Ming, L. K., ...Sakamoto, A. (2009). The effects of prosocial video games on prosocial behaviors: International evidence from correlational, longitudinal, and experimental studies. Personality \&
Social Psychology Bulletin, 35(6), 752-763. doi:10.1177/0146167209333045

Greitemeyer, T. (2011). Effects of prosocial media on social behavior: When and why does media exposure affect helping and aggression? Current Directions in Psychological Science, 20(4), 251255. doi:10.1177/0963721411415229

Greitemeyer, T. (2013a). Intense acts of violence during video game play make daily life aggression appear innocuous: A new mechanism why violent video games increase aggression. Journal of Experimental Social Psychology. doi:10.1016/j. jesp.2013.09.004

Greitemeyer, T. (2013b). Playing video games cooperatively increases empathic concern. Social Psychology, 44(6), 408-413. doi:10.1027/18649335/a000154

Greitemeyer, T. (2013c). Playing violent video games increase intergroup bias. Personality and Social Psychology Bulletin, 1-9. doi:10.1177/ 0146167213505872

Greitemeyer, T., \& Mügge, D. O. (2014). Video games do affect social outcomes: A meta-analytic review of the effects of violent and prosocial video game play. Personality \& Social Psychology Bulletin, 1-12. doi:10.1177/0146167213520459

Greitemeyer, T., \& Osswald, S. (2009). Prosocial video games reduce aggressive cognitions. Journal of Experimental Social Psychology, 45, 896900. doi:10.1016/j.jesp.2009.04.005

Greitemeyer, T., \& Osswald, S. (2010). Effects of prosocial video games on prosocial behavior. Journal of Personality and Social Psychology, 98(2), 211-221. doi:10.1037/a0016997

Greitemeyer, T., Agthe, M., Turner, R., \& Gschwendtner, C. (2011). Acting prosocially reduces retaliation: Effects of prosocial video games on aggressive behavior. European Journal of Social Psychology, 235-242. doi:10.1002/ejsp.1837

Hasan, Y., Bègue, L., \& Bushman, B. J. (2012). Viewing the world through "blood-red tinted glasses": The hostile expectation bias mediates the link between violent video game exposure and aggression. Journal of Experimental Social Psychology, 48, 953-956. doi:10.1016/j. jesp.2011.12.019

Hasan, Y., Bègue, L., Scharkow, M., \& Bushman, B. J. (2013). The more you play, the more aggressive you become: A long-term experimental study of cumulative violent video game effects 
on hostile expectations and aggressive behavior. Journal of Experimental Social Psychology, 49(2), 224-227. doi:10.1016/j.jesp.2012.10.016

Hassin, R. R., Uleman, J. S., \& Bargh, J. A. (Eds.). (2005). The new unconscious. New York: Oxford University Press. doi:10.1093/acprof:o so/9780195307696.001.0001

Huesmann, L. R. (2007). The impact of electronic media violence: Scientific theory and research. The Journal of Adolescent Health, 41(Suppl.), S6-S13. doi:10.1016/j.jadohealth.2007.09.005

Jeong, E. J., Biocca, F. A., \& Bohil, C. J. (2012). Sensory realism and mediated aggression in video games. Computers in Human Behavior, 28(5), 1840-1848. doi:10.1016/j.chb.2012.05.002

Jin, S.-A. A. (2011). "My avatar behaves well and this feels right": Ideal and ought selves in video gaming. Social Behavior and Personality, 39(9), 1175-1182.

Kahneman, D. (2011). Thinking fast and slow. New York: Farrar, Straus and Giroux.

Krahé, B. (2014). Restoring the spirit of fair play in the debate about violent video games. European Psychologist, 19(1), 56-59. doi:10.1027/10169040/a000165

Mäyrä, F. (2008). An introduction to game studies. Thousand Oaks, CA: Sage.

McGonigal, J. (2011). Reality is broken. Why games makes us better and how they can change the world. New York: The Penguin Press.

McMahan, R. P., Ragan, E. D., Leal, A., Beaton, R. J., \& Bowman, D. A. (2011). Considerations for the use of commercial video games in controlled experiments. Entertainment Computing, 2(1), 3-9. doi:10.1016/j.entcom.2011.03.002

Peng, W., Lee, M., \& Heeter, C. (2010). The effects of a serious game on role-taking and willingness to help. Journal of Communication, 60, 723742. doi:10.1111/j.1460-2466.2010.01511.x

Prot, S., \& Anderson, C. A. (2013). Research methods, design, and statistics in media psychology. In K. Dill (Ed.), The Oxford handbook of media psychology (pp. 109-136). New York: Oxford University Press.

Prot, S., Gentile, D. A., Anderson, C. A., Suzuki, K., Swing, E., Lim, K. M., ...Lam, B. C. P. (2013). Long-term relations among prosocial-media use, empathy, and prosocial behavior. Psychological Science. doi:10.1177/0956797613503854
Saleem, M., Anderson, C. A., \& Gentile, D. A. (2012a, January). Effects of prosocial, neutral, and violent video games on college students' affect. Aggressive Behavior, 38, 263-271. doi:10.1002/ab.21427

Saleem, M., Anderson, C. A., \& Gentile, D. A. (2012b). Effects of prosocial, neutral, and violent video games on children's helpful and hurtful behaviors. Aggressive Behavior, 38(4), 281287. doi:10.1002/ab. 21428

Sestir, M. A., \& Bartholow, B. D. (2010). Violent and nonviolent video games produce opposing effects on aggressive and prosocial outcomes. Journal of Experimental Social Psychology, 46, 934-942. doi:10.1016/j.jesp.2010.06.005

Swing, E. L., Gentile, D. A., \& Anderson, C. A. (2009). Learning processes and violent video games. In R. E. Ferdig (Ed.), Handbook of research on effective electronic gaming in education (Vol. 2, pp. 876-892). New York: Information Science Reference.

Tear, M. J., \& Nielsen, M. (2013). Failure to demonstrate that playing violent video games diminishes prosocial behavior. PLoS ONE, 8(7), e68382. doi:10.1371/journal.pone.0068382

Uhlmann, E., \& Swanson, J. (2004). Exposure to violent video games increases automatic aggressiveness. Journal of Adolescence, 27(1), 41-52. doi:10.1016/j.adolescence.2003.10.004

Valadez, J. J., \& Ferguson, C. J. (2012). Just a game after all: Violent video game exposure and time spent playing effects on hostile feelings, depression, and visuospatial cognition. Computers in Human Behavior, 28, 608-616. doi:10.1016/j. chb.2011.11.006

Xu, H., Bègue, L., \& Bushman, B. J. (2012). Too fatigued to care: Ego depletion, guilt, and prosocial behavior. Journal of Experimental Social Psychology, 48(5), 1183-1186. doi:10.1016/j. jesp.2012.03.007

Yao, M. Z., Mahood, C., \& Linz, D. (2010). Sexual priming, gender stereotyping, and likelihood to sexually harass: Examining the cognitive effects of playing a sexually-explicit video game. Sex Roles, 62(1-2), 77-88. doi:10.1007/s11199-0099695-4 